\title{
A MATHEMATICAL MODELLING OF DFIG BASED WIND ENERGY CONVERSION SYSTEM WITH VIRTUAL RESISTANCE
}

\author{
Balavignesh S \\ Assistant Professor, Department of Electrical and Electronics Engineering \\ Bannari Amman Institute of Technology, Sathyamangalam, Tamilnadu, India \\ Jeevanandham A \\ Professor, Department of Electrical and Electronics Engineering \\ Sri Krishna College of Engineering And Technology, Coimbatore, Tamilnadu, India \\ Rishikesh N \\ Assistant Professor, Department of Electrical and Electronics Engineering \\ Bannari Amman Institute of Technology, Sathyamangalam, Tamilnadu, India

\section{Senthil Kumar J} \\ Assistant Professor, Department of Electrical and Electronics Engineering \\ Bannari Amman Institute of Technology, Sathyamangalam, Tamilnadu, India
}

\begin{abstract}
This paper presents the mathematical modelling of DFIG based on load convention and explains the reduction of fault current in the rotor windings. The reduction of fault current is done by using virtual resistance control in which enhanced approach towards Fault Ride Through (FRT) controller is made. The enhanced FRT approach overcomes the usage of the conventional crowbar technique and uses a virtual resistance, where it meets the new grid code requirements during grid faults. Hence the whole system is always connected to the grid during abnormal conditions. The simulations are carried out in MATLAB /SIMULINK and the results are compared with those of the conventional crowbar method.
\end{abstract}

Key words: Doubly Fed Induction Generator, Fault Ride-Through, virtual resistance, virtual inductance, grid fault.

Cite this Article: Balavignesh S, Jeevanandham A, Rishikesh N and Senthil Kumar J, A Mathematical Modelling of DFIG Based Wind Energy Conversion System with Virtual Resistance. International Journal of Electrical Engineering and Technology, 11(6), 2020, pp. 10-24.

http://iaeme.com/Home/issue/IJEET?Volume $=11 \&$ Issue $=6$ 


\section{INTRODUCTION}

Nowadays, wind energy is playing the major role in the power generation sector, where it reduces the use of fossil fuels, which is eco-friendly to the environment and also its cost effective renewable technology too. Recently, Doubly Fed Induction Generator (DFIG) is preferred over others due to variable speed and decoupled control of active and reactive power. The major advantage of doubly fed induction generator is that the rotor side converter takes only $30-50 \%$ of rotor power from the generator rating, whereas in the direct-drive wind power system machines full scale rating are considered. Hence by the use of doubly fed induction generator, converter size is made small which is cost-effective, light-weight and comparatively loss is reduced.

Moving towards the construction of the system, the stator of doubly fed induction generator is connected directly to the AC mains and the wound rotor is fed through back-toback power electronics converter via DC capacitor linking grid-side and rotor-side converters which allows the energy storage for further generation and also DC link voltage should be of higher amplitude than grid line-to-line voltage to have full-fledged control over grid current. On the occurrence of grid disturbance or grid faults, voltage sags is produced in the grid which finally results in over-current in rotor windings and damages the rotor-side converter. Due to this impact there will be a large change in DC link voltages, which leads to torque oscillations and make damage to the converter.

Conventional method of reducing the effects during fault is the use of crowbar technique shown in Fig.1 which protects the rotor side converter by short circuiting the rotor windings. By using a crowbar protection technique, working of DFIG is converted into the conventional squirrel-cage induction generator and hence the machine absorbs more reactive power from the grid and does not fulfill the grid code requirements. The use of crowbar [1] increases the cost of the system and reduces the reliability of the system performance. Hence the increased use of wind energy tends us to improve the fault-ride through capability of wind turbines in order to satisfy the latest grid code criteria under grid disturbance. The absolute necessity to achieve the gird code [25], [26], [28] requirement can be fulfilled by fault-ride through technique towards the DFIG based wind power systems. Nowadays, several methods have been adopted in which the installation of crowbar, static synchronous compensator or additional series converters [2], [3], [4] is used to reduce the effects during a fault. These techniques increase the cost and complexity of the system.

The major objective of this paper deals with the enhanced approach towards the reduction of fault current in the rotor windings during grid disturbance. This approach is made without using active crowbar, static synchronous compensator and a tripping converter is shown in Fig.2. In this paper, the proportional partial feedback model is used which is also called as virtual resistance is proposed in this control strategy. By taking this into account, over-current is produced in the rotor and the time of oscillation can be greatly reduced and hence this improves the system damping during grid faults. The overall performance can be improved where it provides an online approach of the overall system during the grid disturbance, [15], [20] further there won't be any disconnection between the grid and source and hence the voltage is recovered to fulfill the grid code by injecting the reactive power, this is carried out in our new improved approach during grid fault. It also includes the demagnetizing effect [22], [23], [24] to neutralize the DC and the negative component of the stator.

This paper has been presented in the following manner: Section II presents the mathematical modeling of DFIG using load convection. Section III presents the proposed control strategy using virtual resistance. Section IV presents the simulative results and finally Section V summarizes the conclusion. 


\section{MATHEMATICAL MODEL OF DFIG}

The mathematical modelling of DFIG is developed by taking the overall system under load convention. Synchronous and induction machine inductances are functions of the rotor speed, therefore the coefficients of the differential equations (voltage equations) which describe the behavior of these machines [5], [9], [11], [12], [14] are time-varying. A change of variables can be used to reduce the complexity of machine differential equations, and represent these equations in another reference frame with constant coefficients. A change of variables which formulates a transformation of the 3-phase variables of stationary circuit elements to the arbitrary reference frame may be expressed as

$$
\begin{aligned}
& \mathrm{f}_{\mathrm{qd} 0 \mathrm{~s}}=\mathrm{K}_{\mathrm{s}} * \mathrm{f}_{\mathrm{abcs}} \\
& \text { where, }\left(f_{q d 0 s}\right)^{T}=\left[f_{q s} f_{d s} f_{0 s}\right] \\
& \left(f_{\text {abcs }}\right)^{T}=\left[f_{a s} f_{b s} f_{c s}\right] \\
& \mathrm{K}_{\mathrm{s}}=\frac{2}{3}\left[\begin{array}{ccc}
\cos \theta & \cos \left(\theta-\frac{2 \Pi}{3}\right) & \cos \left(\theta+\frac{2 \Pi}{3}\right) \\
\sin \theta & \sin \left(\theta-\frac{2 \Pi}{3}\right) & \sin \left(\theta+\frac{2 \Pi}{3}\right) \\
\frac{1}{2} & \frac{1}{2} & \frac{1}{2}
\end{array}\right] \\
& \mathrm{K}_{\mathrm{s}}^{-1}=\left[\begin{array}{ccc}
\cos \theta & \sin \theta & 1 \\
\cos \left(\theta-\frac{2 \Pi}{3}\right) & \sin \left(\theta-\frac{2 \Pi}{3}\right) & 1 \\
\cos \left(\theta+\frac{2 \Pi}{3}\right) & \sin \left(\theta+\frac{2 \Pi}{3}\right) & 1
\end{array}\right]
\end{aligned}
$$

"f" can represent either voltage, current, or flux linkage. "s" indicates the variables, parameters and transformation associated with stationary circuits where " $\omega$ " represent the speed of reference frame and all these variables in dq reference are shown in Fig.3. In this paper, machine modeling has been derived by considering $\omega=\omega_{\mathrm{e}}$ which represents synchronously rotating reference frame. $f_{a s}, f_{b s}$ and $f_{c s}$ may be thought of as the direction of the magnetic axes of the stator windings. $f_{\mathrm{qs}}$ and $\mathrm{f}_{\mathrm{ds}}$ can be considered as the direction of the magnetic axes of the new fictitious windings located on $\mathrm{q}_{\mathrm{s}}$ and $\mathrm{d}_{\mathrm{s}}$ axis which are created by the change of variables. Power Equations corresponding to the transformations is given by

$$
\begin{gathered}
P_{a b c s}=V_{a s} I_{a s}+V_{b s} I_{b s}+V_{c s} I_{c s} \\
P_{q d 0 s}=\frac{2}{3} P_{a b c s}=\frac{2}{3}\left(V_{a s} I_{a s}+V_{b s} I_{b s}+V_{c s} I_{c s}\right)
\end{gathered}
$$

Consider the stator windings of a symmetrical induction or round rotor synchronous machine shown in Fig.4, for which the inductance matrix is given below,

$$
\begin{gathered}
r_{s}=\operatorname{diag}\left[r_{s} r_{s}\right. \\
L_{s}=\left[\begin{array}{ccc}
L s & M & M \\
M & L s & M \\
M & M & L s
\end{array}\right]
\end{gathered}
$$

Where $L_{s}=L_{l s}+L_{m s}$

$$
M=-\frac{1}{2} L_{m s}
$$

For each phase voltage, we write the following equations,

$$
\begin{gathered}
\mathrm{V}_{\mathrm{as}}=\mathrm{r}_{\mathrm{s}} \mathrm{I}_{\mathrm{as}}+\rho \lambda_{\mathrm{as}}, \\
\mathrm{V}_{\mathrm{qd} 0 \mathrm{~s}}=\mathrm{K}_{\mathrm{s}} \mathrm{V}_{\mathrm{abcs}} \\
\mathrm{V}_{\mathrm{bs}}=\mathrm{r}_{\mathrm{s}} \mathrm{I}_{\mathrm{bs}}+\rho \lambda_{\mathrm{bs}} \\
I_{q d 0 s}=K_{s} I_{a b c s} \\
V_{c s}=r_{s} I_{c s}+\rho \lambda_{c s}
\end{gathered}
$$




$$
\begin{aligned}
& \lambda_{q d 0 s}=K_{s} \lambda_{a b c s} \\
& \lambda_{a b c s}=L_{s} I_{a b c s}
\end{aligned}
$$

In Vector form,

$$
\mathrm{V}_{\mathrm{abcs}}=\mathrm{r}_{\mathrm{s}} \mathrm{I}_{\mathrm{abcs}}+\rho \lambda_{\mathrm{abcs}}
$$

$\backslash$ Multiplying by $\mathrm{K}_{\mathrm{s}}$,

$$
K_{s} V_{a b c s}=K_{s} r_{s} I_{a b c s}+K_{s} \rho \lambda_{a b c s}
$$

Replace $\mathrm{I}_{\mathrm{abcs}}$ and $\lambda_{\mathrm{abcs}}$ using the transformation equations. we obtain the following,

$$
\begin{gathered}
\mathrm{K}_{\mathrm{s}} \mathrm{V}_{\mathrm{abcs}}=\mathrm{K}_{\mathrm{s}}\left(\mathrm{r}_{\mathrm{s}} \mathrm{K}_{\mathrm{s}}^{-1} \mathrm{I}_{\mathrm{qd} 0 \mathrm{~s}}\right)+\mathrm{K}_{\mathrm{s}} \rho\left(\mathrm{K}_{\mathrm{s}}{ }^{-1} \lambda_{\mathrm{qd} 0 \mathrm{~s}}\right) \\
\mathrm{V}_{\mathrm{qd} 0 \mathrm{~s}}=\mathrm{r}_{\mathrm{s}} \mathrm{I}_{\mathrm{qd} 0 \mathrm{~s}}+\dot{\mathrm{w}} \lambda_{\mathrm{qd} 0 \mathrm{~s}} \\
\mathrm{~V}_{\mathrm{qs}}=\mathrm{r}_{\mathrm{s}} \mathrm{I}_{\mathrm{qs}}+\omega \lambda_{\mathrm{ds}}+\rho \lambda_{\mathrm{qs}} \\
\lambda_{\mathrm{qs}}=\left(\mathrm{L}_{\mathrm{s}}-\mathrm{M}\right) \mathrm{I}_{\mathrm{qs}} \\
\mathrm{V}_{\mathrm{ds}}=\mathrm{r}_{\mathrm{s}} \mathrm{I}_{\mathrm{ds}}-\omega \lambda_{\mathrm{qs}}+\rho \lambda_{\mathrm{ds}} \\
\lambda_{\mathrm{ds}}=\left(\mathrm{L}_{\mathrm{s}}-\mathrm{M}\right) \mathrm{I}_{\mathrm{ds}} \\
\mathrm{V}_{0 \mathrm{~s}}=\mathrm{r}_{\mathrm{s}} \mathrm{I}_{0 \mathrm{~s}}+\rho \lambda_{0 \mathrm{~s}} \\
\lambda_{0 \mathrm{~s}}=\left(\mathrm{L}_{\mathrm{s}}+2 \mathrm{M}\right) \mathrm{I}_{0 \mathrm{~s}}
\end{gathered}
$$

Where

$$
\dot{w}=\omega\left[\begin{array}{ccc}
0 & 1 & 0 \\
-1 & 0 & 0 \\
0 & 0 & 0
\end{array}\right]
$$

\subsection{Equivalent Circuit of IM in d-q axis}

The equivalent circuit for $\mathrm{q}, \mathrm{d}$ and 0 -axis which are transformed to synchronously rotating reference frame is shown in Fig. 5. The stationary circuit variables $\omega=\omega_{\mathrm{e}}$ in the synchronously rotating reference frame [6], [7], [10], [12] are referred as $\mathrm{f}_{\mathrm{qd} 0 \mathrm{~s}}^{\mathrm{e}}$ or $\mathrm{f}_{\mathrm{qs}}^{\mathrm{e}}, \mathrm{f}_{\mathrm{ds}}^{\mathrm{e}}$ and $\mathrm{f}^{\mathrm{e}}{ }_{0 \mathrm{~s}}$ and transformation matrix is designated as $\mathrm{K}_{\mathrm{s}}^{\mathrm{e}}$. Similarly the rotor side of the DFIG machine can be transformed to the desired reference frames and the equations are obtained as follows,

$$
\begin{aligned}
& V_{q r}=r_{r} I_{q r}+\left(\omega-\omega_{r)} \lambda_{d r}+\rho \lambda_{q r}\right. \\
& \lambda_{q r}=L_{r} I_{q r}+L_{m} I_{q s} \\
& V_{d r}=r_{r} I_{q r}-\left(\omega-\omega_{r}\right) \lambda_{q r}+\rho \lambda_{d r} \\
& \lambda_{d r}=L_{r} I_{d r}+L_{m} I_{d s}
\end{aligned}
$$

\section{PROPOSED CONTROL STRATEGY}

In this paper, an enhanced approach of fault-ride through control is proposed in order to reduce the over-current in the rotor winding during grid disturbance and the layout of the proposed control strategy is shown in Fig.6. The comparative analysis has been carried out by using the normal vector controller and fault ride through controller in the proposed control strategy. In the normal vector controller, the stator flux oriented control scheme is used where the decoupled action of real and reactive power [17], [18], [19], [28] can be achieved during normal condition and hence the power equations can be expressed as,

$$
\begin{gathered}
P_{s}=V_{q s} I_{q s} \\
Q_{s}=V_{q s} I_{d s}
\end{gathered}
$$


Therefore, the above equation shows that real and reactive power can be independently controlled. Since the inductance matrix is not diagonal and hence the system is not coupled. To overcome this problem, leakage factor is included to compensate the cross coupling between $\mathrm{d}$ and $\mathrm{q}$ axes and hence its re-developed as,

$$
\sigma=1-\frac{L_{m}^{2}}{\left(L_{l s}+L_{m}\right)\left(L_{l r}+L_{m}\right)}
$$

The theoretical basis of a fault ride through controller in the proposed strategy is the proportional partial controller is made by using the virtual resistance control and demagnetizing control is also included to limit the rotor current and by increasing the leakage inductance of the rotor demagnetizing current can be decreased. Hence the use of crowbar can be removed. At the same time reactive power should be injected into the grid during voltage sag to meet the grid code requirement. Therefore the proposed fault ride through controller consists of the proportional partial control block, demagnetizing control and reactive power injection block. The smooth switching is also performed from normal control to proposed fault ride through controller during grid disturbance.

\subsection{Virtual Resistance Control}

The equivalent circuit of DFIG model is described for the system with and without virtual resistance. The equivalent circuit of without virtual resistance is shown in Fig.7 and the transfer function $G_{d}(s)$ for current loop in rotor converter is expressed as

$$
G_{o}(s)=\frac{K}{R_{r}+\sigma L_{r} s}
$$

After the inclusion of virtual resistance effects as the proportional partial feedback circuit which in turn prevent the influence of the disturb term. This virtual resistance improves the dynamic performance or characteristics of the system and hence reduces the time constant.

Fig. 8 shows the equivalent circuit of DFIG with virtual resistance and the transfer function obtained is given by,

$$
G_{v}(s)=\frac{K}{\left(R_{r}+K \cdot R_{v}\right)+\left(\sigma L_{r}+K \cdot L_{v}\right) s}
$$

The equivalent circuit of the DFIG after partial feedback is that the inclusion of resistor in series with the DFIG rotor circuit and hence it can be expressed as K. $\mathrm{R}_{\mathrm{v}}$. The addition of series resistor in the equivalent circuit reduces the effect of EMF on the rotor circuit $\mathrm{ir}_{\mathrm{r}}^{\mathrm{r}}$. This resistor is termed as "virtual resistor" which originally does not exist. Likewise virtual inductance can also be added in the feedback and hence it can be expressed as $L_{f} s$.

The equivalent circuit considering both virtual resistance and virtual inductance is shown in Fig.9 and hence the transfer function of the circuit is expressed as,

$$
G_{v}(s)=\frac{K}{\left(R_{r}+K \cdot R_{v}\right)+\left(\sigma L_{r}+K \cdot L_{v}\right) s}
$$

Now the fact shows that the addition of virtual resistance and virtual inductance reduces the rotor current and hence improves the dynamic performance during grid faults. By using virtual resistance control the leakage inductance of the stator and rotor of DFIG is made smaller. Hence the transitory oscillation gets reduced. By making use of this, the improved performance can be obtained from the approach towards fault-ride through capability. Hence 
the proposed FRT controller improves the system performance. The equation can also be derived as,

$$
G_{o}(s)=\frac{K_{o}}{1+T_{0} s}
$$

Where $K_{o}=\frac{K}{R_{r}}, T_{o}=\frac{\sigma L_{r}}{R_{r}}$

After the inclusion of virtual resistance the transfer function can be re-written as

$$
\begin{gathered}
G_{v}{ }^{\prime}(s)=\frac{K_{o}{ }^{\prime}}{1+T_{0}{ }^{\prime} s} \\
\text { Where } K_{o}{ }^{\prime}=\frac{K_{o}}{1+\left(R_{v} K_{o}\right)}, T_{o}^{\prime}=\frac{T_{0}}{1+R_{v} K_{o}}
\end{gathered}
$$

Hence after the inclusion of virtual resistance the parameter variation is reduced by $1 /\left(1+R_{V} K_{o}\right)$ times the original value. This makes less sensitive to the control over parameter variation of DFIG where the relative proportion of the variation over machine parameter gets decreased.

\subsection{Demagnetization Control}

Since the main cause of over-current production is due to DC component and negative component in the stator flux during grid faults. Hence the rotor current can be controlled by acting against the DC and negative component in the stator flux linkage. The rotor current components are against the DC flux component and negative component, where the two components are counteracted and the consequence of these components is made to weaken. To carry out demagnetization control the following steps should be carried out; first the approximate calculation of stator flux linkage is calculated, then rotor current reference is estimated and finally control action is carried out. During grid voltage dip, the DC and negative component values are determined and hence demagnetization current would be very large during the deep dip. The analysis is made by adding virtual resistance and virtual inductance where the virtual resistance reduces transitory oscillation and virtual inductance reduces demagnetizing current; hence the control range is enlarged and the crowbar is eliminated. The virtual resistance and inductance value should be calculated by considering the rotor current range during grid fault and also the constraints should be made not to exceed the maximum permissible range. By considering the criteria tuning of virtual resistance and inductance is made by simulating in the proposed system.

\subsection{Reactive Power Compensation}

The overall system criterion is fulfilled when the requirement of grid code [21]-[24], [8] is satisfied. This can be achieved by injecting reactive power to the grid in order to support the grid voltage recovery during grid disturbance. This defines the term reactive power compensation. The acceptable grid code E.ON provides the information that the network voltage must be provided with $20 \mathrm{~ms}$ after fault identification. This is done by supplying reactive power at the generator terminals; therefore the dip depth is calculated and relative to this the reactive power is injected in order to provide reactive power compensation. According to grid voltage dip the reactive power gets injected into the grid. 


\section{FIGURES}

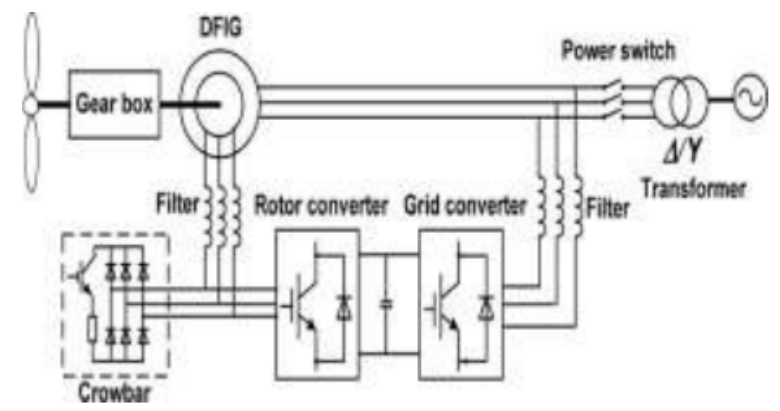

Figure 1 DFIG-based wind turbine equipped with crowbar

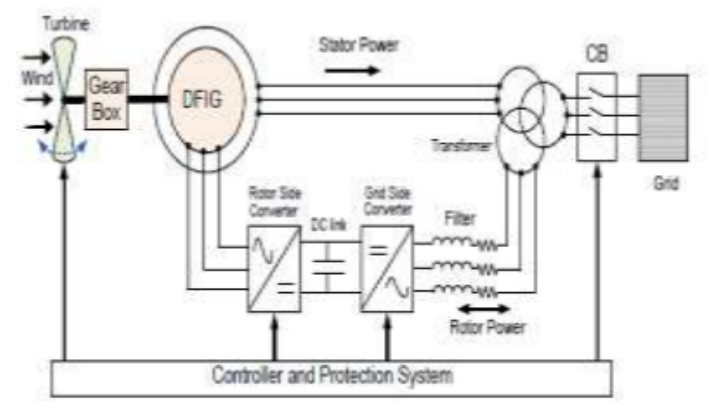

Figure 2 DFIG-based wind turbine without using crowbar

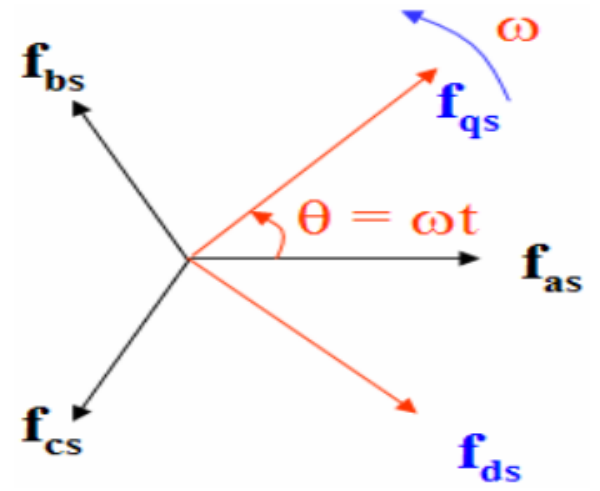

Figure 3 Stator variables in d-q reference frame

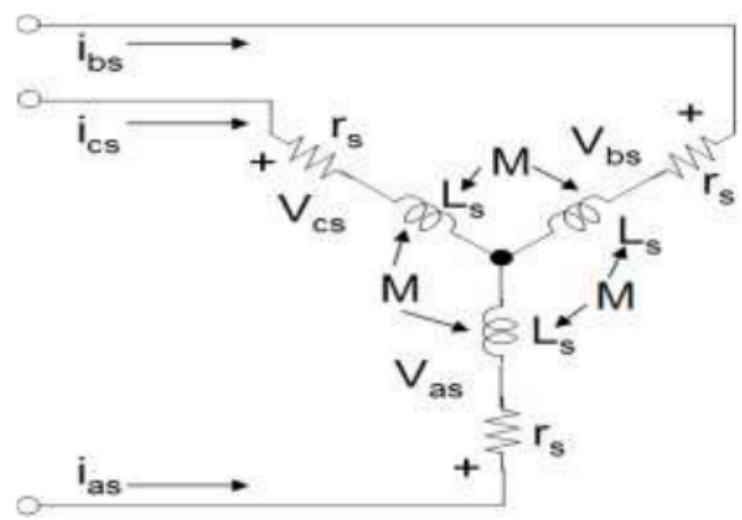

Figure 4 Stator windings of the Induction Motor 


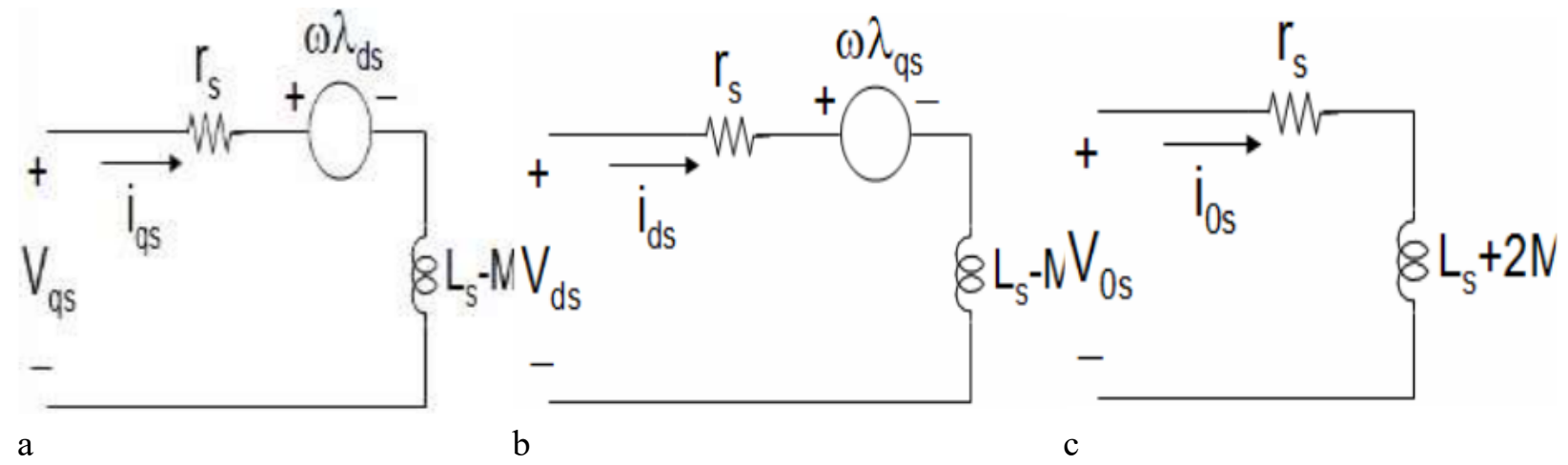

Figure 5 Equivalent circuit of induction machine in a) q-axis b) d-axis c) 0 -axis

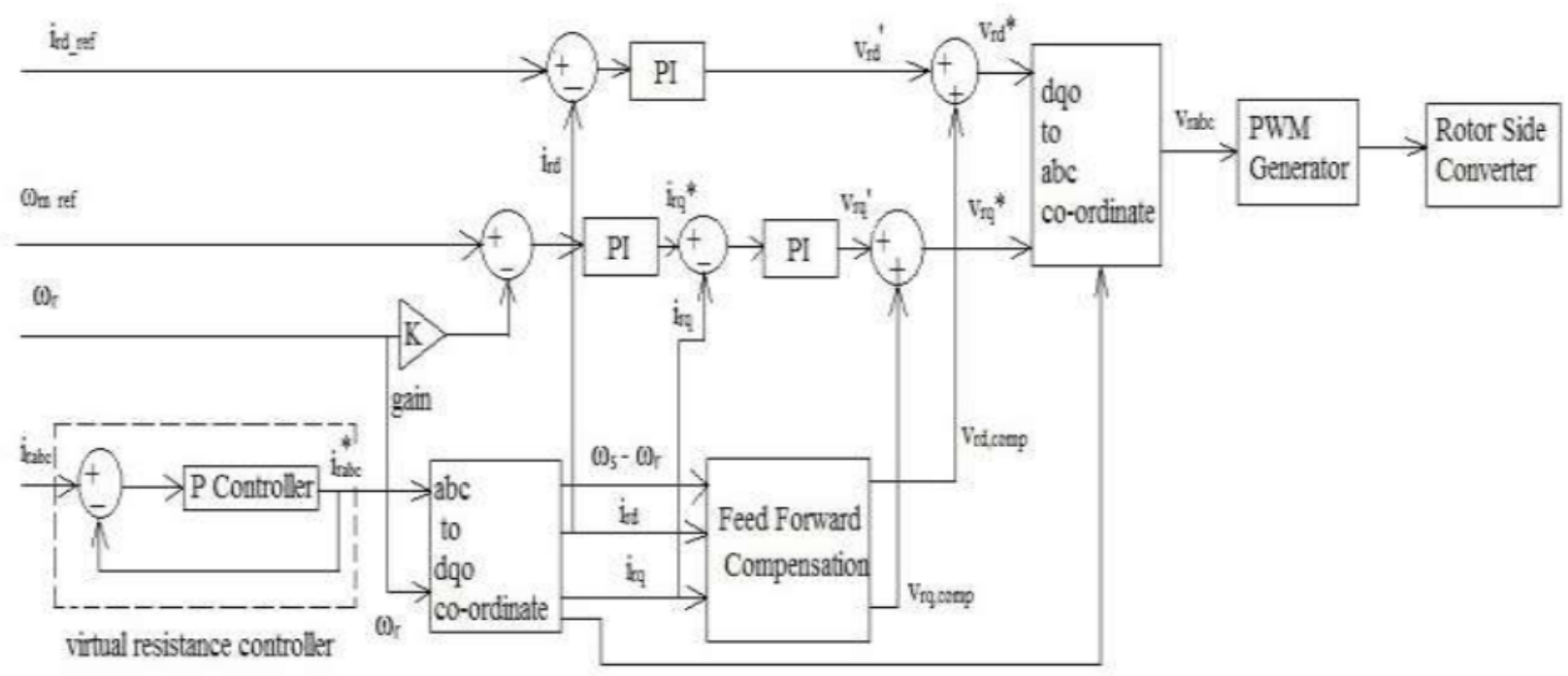

Figure 6 Proposed control scheme

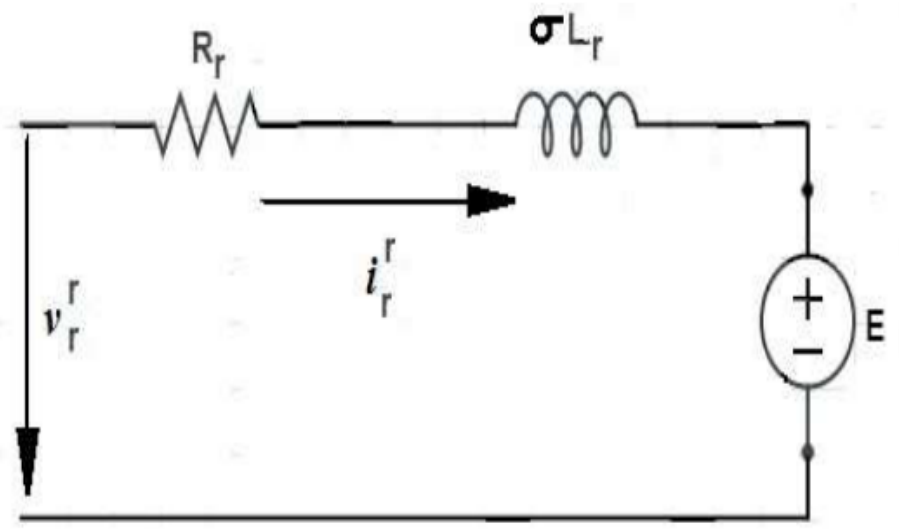

Figure 7 Equivalent DFIG model viewed from rotor side 
Balavignesh S, Jeevanandham A, Rishikesh N and Senthil Kumar J

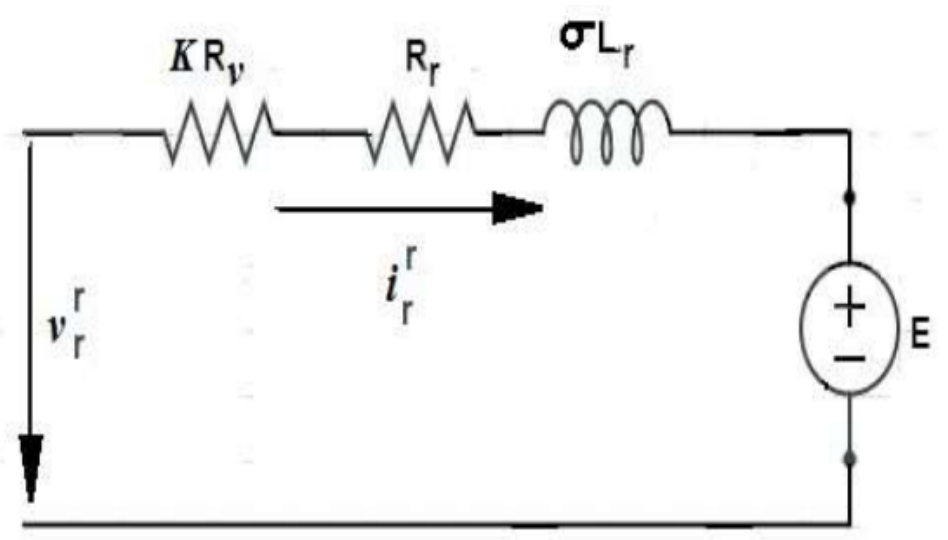

Figure 8 Equivalent circuit of the DFIG with virtual resistance

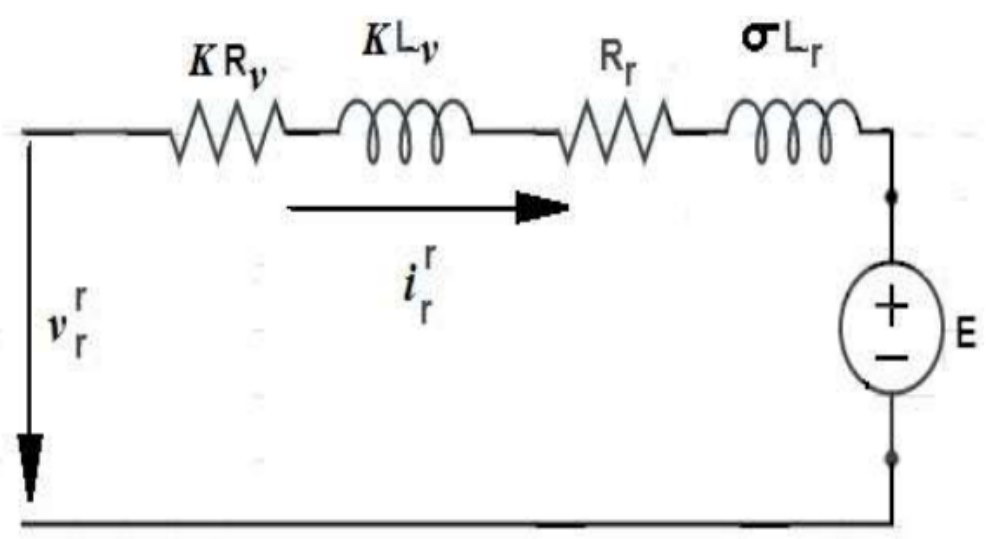

Figure 9 Equivalent circuit with virtual resistance and inductance

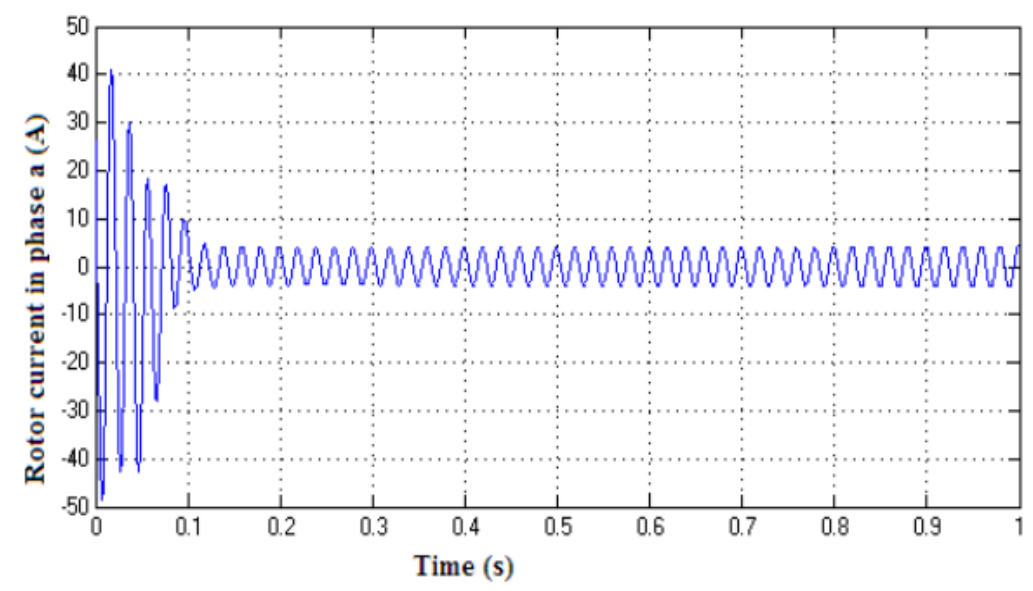

Figure 10 Rotor current in phase-a during normal condition 


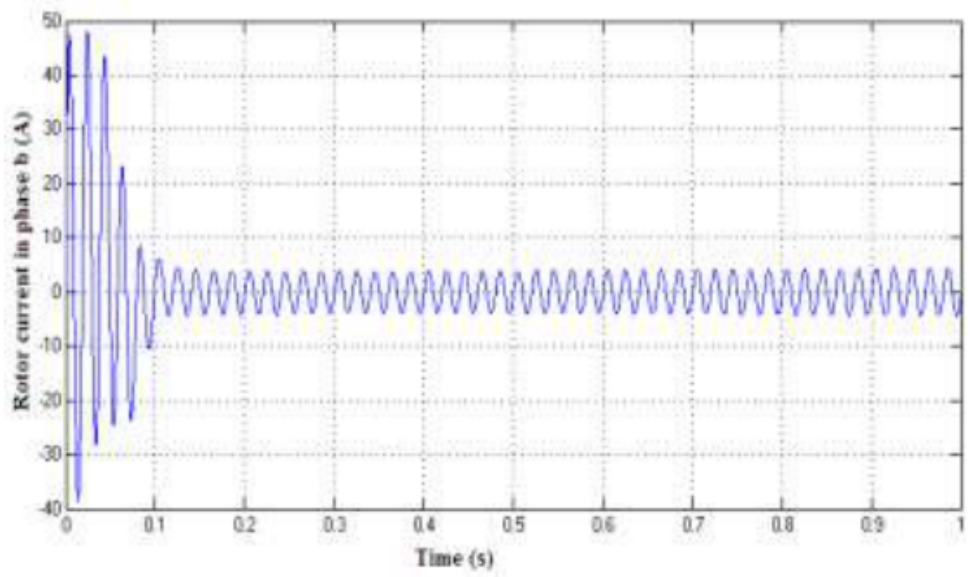

Figure 11 Rotor current in phase-b during normal condition

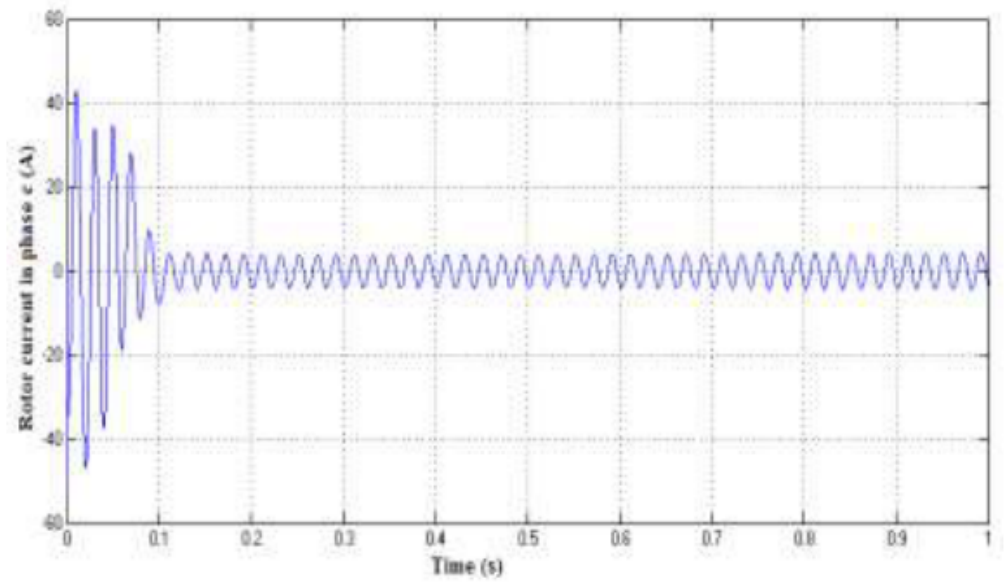

Figure 12 Rotor current in phase-c during normal condition

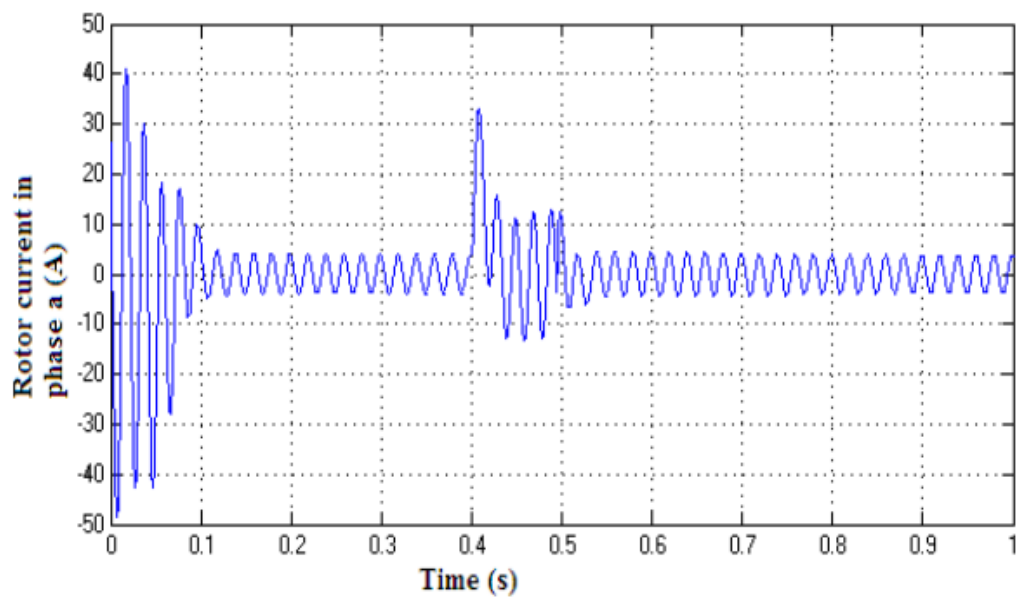

Figure 13 Rotor current in phase-a during grid fault using normal vector controller 
Balavignesh S, Jeevanandham A, Rishikesh N and Senthil Kumar J

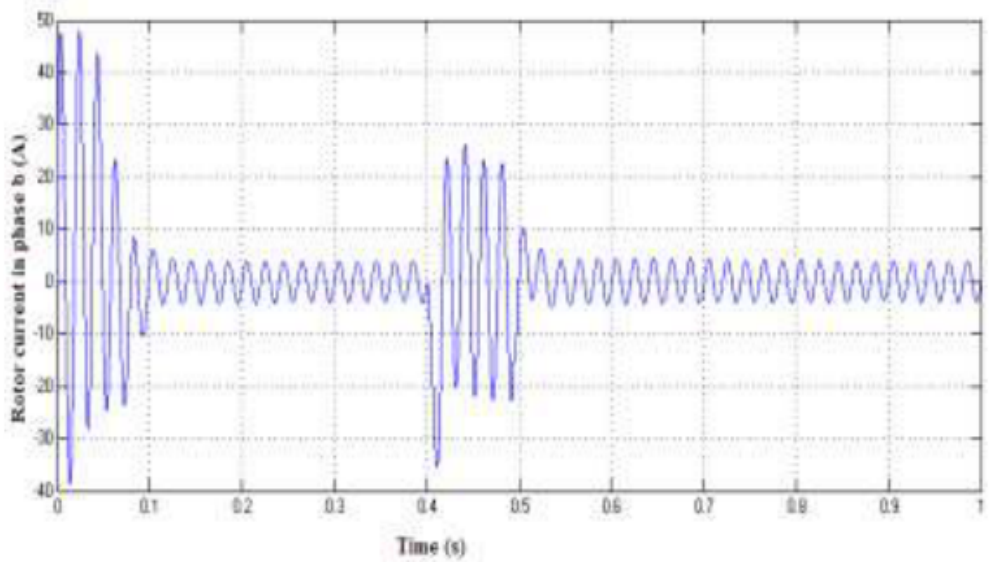

Figure 14 Rotor current in phase-b during grid fault using normal vector controller

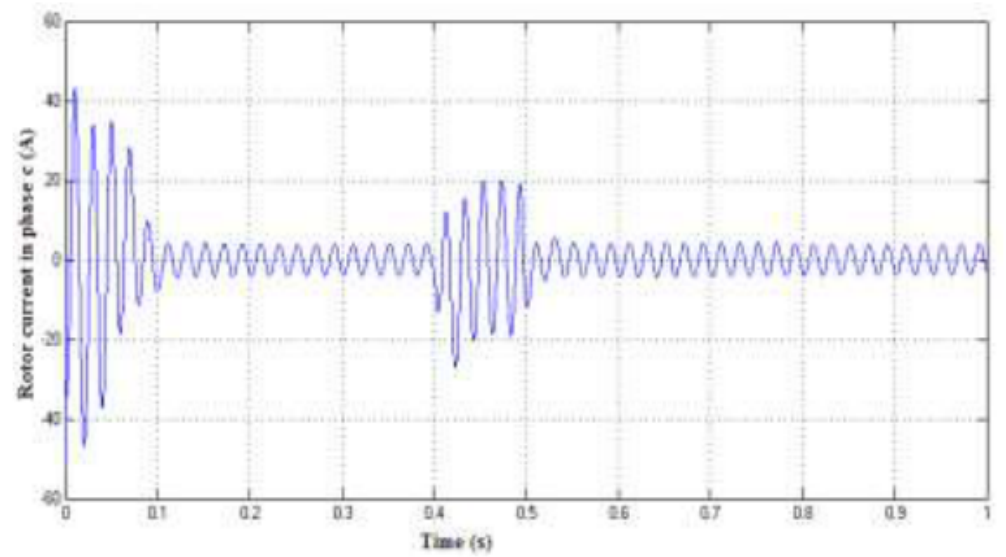

Figure 15 Rotor current in phase-c during grid fault using normal vector controller

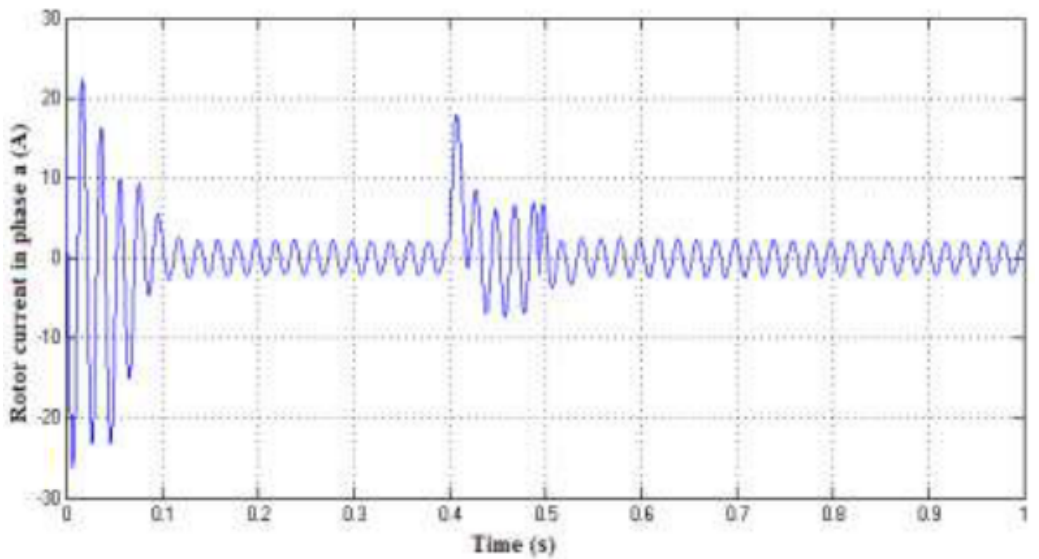

Figure 16 Rotor current in phase-a during grid fault using FRT controller. 


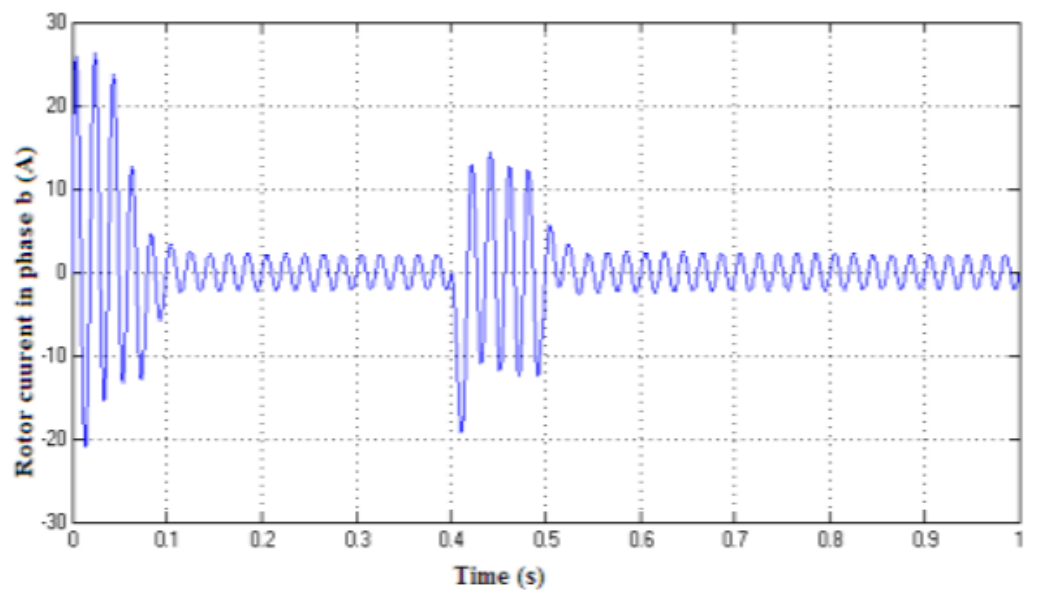

Figure 17 Rotor current in phase-b during grid fault using FRT controller.

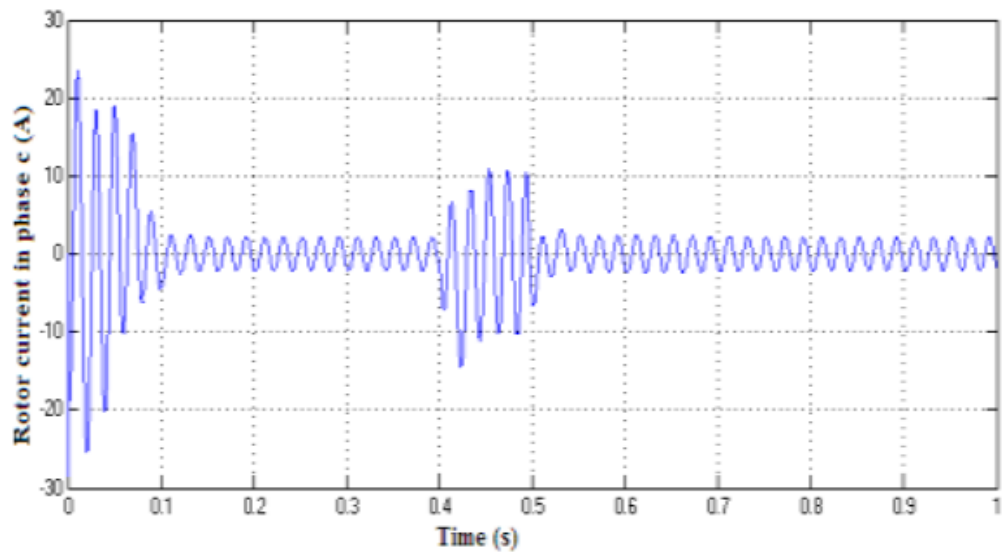

Figure 18 Rotor current in phase-c during grid fault using FRT controller.

\section{SIMULATION RESULTS}

The fault ride-through capability has been evaluated with $100 \%$ of voltage sags in which virtual resistance value has been taken by considering worst case. The simulative parameter of DFIG system is given in Appendix I. Fig.10, 11, 12 shows the rotor current of phase a, $b$ and c respectively without grid voltage dip. Fig.13, 14, 15 shows the rotor current of phase a, b and c respectively with normal stator flux oriented vector controller during the grid voltage dip. Fig. 16, 17, 18 shows the rotor current of phase a, b and c respectively with fault ridethrough controller during the grid voltage dip.

In this system maximum permissible rotor current range is of $32 \mathrm{~A}$; however, during grid voltage dip the rotor current exceeds the maximum permissible range while using normal stator flux oriented vector controller which in turn damages the converter. But by using fault ride-through controller the rotor current gets limited to 16-18A. Hence the rotor voltage with virtual resistance control is higher than demagnetizing control. Moreover, the rotor current is lower than the maximum permissible value of the rotor converter and hence the rotor currents are controlled in safe zone; whereas the crowbar utility is cancelled.

\section{CONCLUSION}

In this paper, fault ride-through control strategy is proposed which is done by virtual resistance control and demagnetizing control. Here in the proposed control virtual resistance is made to enlarge the control range and hence fault ride-through capability is improved 
which increases the rotor resistance during grid disturbance. Therefore, the combined action due to virtual resistance control and demagnetizing control enlarge the control range of rotor current which consequently cancels the crowbar action. The proposed control strategy of fault ride-through capability has been established by their simulative results. In order to meet the latest grid code requirement, reactive power can be injected to the power grid with proposed control strategy.

\section{REFERENCES}

[1] Honglin Zhou., Geng Yang, Short Circuit Current Analysis of DFIG Wind Turbines with Crowbar Protection, $12^{\text {th }}$ International Conference on Electrical Machines and Systems, pp. 16, 2009.

[2] M.Molinas, J.A.Saul and T. Undeland, Low voltage ride through of wind farms with cage generators: STATCOM versus SVC, IEEE Trans. Power Electron., vol. 23, no. 3, pp. 11041117, May 2008.

[3] C. Shen, Z. Yang, M. L. Crow, and S. Atcitty, Control of STATCOM with energy storage device, in Proc. IEEE Power Engineering Society Winter Meeting, Jan. 23-27, 2000, pp. $2722-2728$.

[4] W. Qiao, G. K. Venayagamoorthy, and R. G. Harley, Real-time implementation of a STATCOM on a wind farm equipped with doubly fed induction generators, IEEE Trans. Ind. Appl., vol. 45, no. 1, pp. 1073- 1080, Jan./Feb. 2009.

[5] Jiabing Hu, Yikang He, Modelling and Enhanced control of DFIG under unbalanced grid voltage conditions, International Journal of Electric Power Systems Research, 2009; 79: 273 281.

[6] A.H.M.A.Rahim, I.O.Habiballah, DFIG rotor voltage control for System Dynamic performance Enhancement, International Journal of Electric Power Systems Research, 2011; 81: $503-509$.

[7] J. Lopez, P. Sanchis, X. Roboam, and L. Marroyo, Dynamic behavior of the doubly-fed induction generator during three-phase voltage dips, IEEE Trans. Energy Convers., vol. 22, no. 3, pp. 709-717, Sep. 2007.

[8] J. Yao, H. Li, Y. Liao, and Z. Chen, An improved control strategy of limiting the dc-link voltage fluctuation for a doubly fed induction wind generator, IEEE Trans. Power Electron., vol. 23 no. 3, pp. 1205-1213, May. 2008.

[9] G. F. Yuan, J. Y. Chai, and Y. D. Li, Vector control and synchronization of doubly fed induction wind generator system, in Proc. 2004 Int. Power Electron. Motion Control Conf., pp. 886-890.

[10] J. Morren and S. W. H. de Haan, Ride through of wind turbines with doubly-fed induction generator during a voltage dip, IEEE Trans. Energy Convers., vol. 20, no. 2, pp. 435-441, Jun. 2005.

[11] V.N. Pande, U.M. Mate, Shailaja Kurode, Discrete Sliding mode control strategy for direct real and reactive power regulation of wind driven DFIG, International Journal of Electric Power Systems Research, 2013; 100: 73 - 81.

[12] L. G.Meegahapola, T. Littler, and D. Flynn, Decoupled-DFIG fault ride-through strategy for enhanced stability performance during grid faults, IEEE Trans. Sustainable Energy, no. 3, pp. 152-162, Oct. 2010.

[13] Anca D. Hansen, Gabriele Michalke, Fault ride-through capability of DFIG wind turbines, International Journal of Electrical power and Energy systems, 2007; 32: 1594-1610. 
[14] Zhanfeng Song, Changliang Xia, Tingna Shi, Assessing Transient response of DFIG based wind turbines during vcoltage dips regarding main flux saturation and rotor deep-bar effect, International Journal of Applied energy, 2010; 87: 3283 - 3293.

[15] J. Yao, H. Li, Y. Liao, and Z. Chen, An improved control strategy of limiting the DC-link voltage fluctuation for a doubly fed induction wind generator, IEEE Trans. Power Electron., vol. 3, no. 23, pp. 1205-1213, May. 2008.

[16] R. Aghatehrani, L. Fan, and R. Kavasseri, Coordinated reactive power control of DFIG rotor and grid sides converters, in Proc. IEEE PES 2009 General Meeting, Calgary, 2009, pp. 1-6.

[17] M. Kayýkçý and J. V. Milanovic, Reactive power control strategies for DFIG-based plants, IEEE Trans. Energy Conversion, vol. 22, no. 2, pp. 389-396, Jun. 2007.

[18] M. Kayikci and J. V.Milanovic, Reactive power control strategies for DFIG-based plants, IEEE Trans. Energy Convers., vol. 22, no. 2, pp. 389-396, Jun. 2007.

[19] B. C. Rabelo, W. Hofmann, J. Lucas da Silva, R. Gaiba de Oliveira, and S. Rocha Silva, Reactive power control design in doubly fed induction generators for wind turbines, IEEE Trans. Ind. Electron., vol. 56, no.10, pp. 4154-4162, Oct. 2009.

[20] Yang Liao, Hui Li, Jan Yao, Kai Zhuang, Operation and control of a grid- connected DFIGbased wind turbine with Series grid-side converter during network unbalance, International Journal of Electric Power Systems Research, 2011; 81: 228 - 236.

[21] J. Morren and S. W. H. de Haan, Short-circuit current of wind turbines with doubly fed induction generator, IEEE Trans. Energy Convers., vol. 22, no. 1, pp. 174-180, Mar. 2007.

[22] A. Dobakhshari and M. Fotuhi-Firuzabad, A reliability model of large wind farms for power system adequacy studies, IEEE Trans. Energy Convers., vol. 24, no. 3, pp. 792-801, Sep. 2009.

[23] Jiabing Hu, Yikang He, DFIG wind generation systems operating with limited converter rating considered under unbalanced network conditions - Analysis and control design, International Journal of Electric Power Systems Research, 2011; 36: 829 - 847.

[24] M. Rahimi and M. Parniani, Coordinated control approaches for low voltage ride-through enhancement in wind turbines with doubly fed induction generators, IEEE Trans. Energy Convers., vol. 25, no. 3, pp. 873-883, Sep. 2010.

[25] B. Andresen and K. Johansen, Grid code and wind farm control requirements-What to control, why, where and how, in Proc. 7th Int. Workshop Large Scale Integr. Wind Power Transmiss. Netw. Offshore Wind Farms, Madrid, Spain, 26-27 May 2008, pp. 1-6.

[26] M Tsili, S Papathanassiou, A review of grid code technical requirements for wind farms, IET Renewable Power Generation, vol.3, iss .3, pp.308-332, Mar. 2008.

[27] T. Thiringer, A. Petersson, and T. Petru, Grid disturbance response of wind turbines equipped with induction generator and doubly-fed induction generator, in Proc. Power Eng. Soc. Annu. Meeting, Toronto, ON, Canada, Jul. 2003, pp. 1542-1547.

[28] S. Z. Chen,N.C.Cheung, K. C.Wong, and J.Wu, Grid synchronization of doubly-fed induction generator using integral variable structure control, IEEE Trans. Energy Convers., vol. 24, no. 4, pp. 875-883, Dec. 2009. 


\section{APPENDIX I}

The parameters of DFIG in the simulation test are shown.

\section{Simulative Parameters of the DFIG}

\begin{tabular}{ll} 
Rated power & $2.23 \mathrm{~kW}$ \\
Rated stator voltage & $440 \mathrm{~V}$ \\
Rated frequency & $50 \mathrm{~Hz}$ \\
Stator resistance & $0.435 \Omega$ \\
Rotor resistance & $0.816 \Omega$ \\
Stator inductance & $0.408 \mathrm{H}$ \\
Rotor inductance & $0.413 \mathrm{H}$ \\
Pole pairs & 2 \\
Moment of inertia & 0.089 \\
\hline \hline
\end{tabular}

